University of Vermont

UVM ScholarWorks

Public Health Projects, 2008-present

Public Health Projects, University of Vermont

College of Medicine

$1-20-2016$

\title{
Parental Perceptions of Oral Health and School-Based Dental Sealant Programs
}

Laura Donnelly

Peter Evans

Ian Grant

Allicia Imeda

Daniel Kula

See next page for additional authors

Follow this and additional works at: https://scholarworks.uvm.edu/comphp_gallery

Part of the Community Health and Preventive Medicine Commons, and the Health Services Research Commons

\section{Recommended Citation}

Donnelly, Laura; Evans, Peter; Grant, Ian; Imeda, Allicia; Kula, Daniel; Park, Clare; Wu, Hao Fang; Cole, Julie; Fontaine, Kristin; and Davis, Wendy, "Parental Perceptions of Oral Health and School-Based Dental Sealant Programs" (2016). Public Health Projects, 2008-present. 232.

https://scholarworks.uvm.edu/comphp_gallery/232

This Book is brought to you for free and open access by the Public Health Projects, University of Vermont College of Medicine at UVM ScholarWorks. It has been accepted for inclusion in Public Health Projects, 2008-present by an authorized administrator of UVM ScholarWorks. For more information, please contact scholarworks@uvm.edu. 


\section{Authors}

Laura Donnelly, Peter Evans, Ian Grant, Allicia Imeda, Daniel Kula, Clare Park, Hao Fang Wu, Julie Cole, Kristin Fontaine, and Wendy Davis 
University of Vermont College of Medicine, ${ }^{2}$ University of Vermont Medical Center

Introduction

Community Health Needs Assessment (University of Vermont Medical Center, 2013)

- Identified oral health in pediatric population as a primary concern

- Barriers to dental care cited: access, affordability, education

School-Based Sealant Program (SBSP)

- Dental sealants are an evidence-based method of cavity prevention ${ }^{2}$

- $\mathrm{CDC}$ strongly recommends delivery via $\mathrm{SBSP}^{3}$

- Few Vermont schools have such a program

Vermont Medicaid State Plan amendment allows dental hygienists to bill without on-site dentist (2015)

- Unique opportunity to pilot an SBSP

- Pilot program implemented by the University of Vermont Medical Center

- Community Health Improvement

- Goal: sustainable model able to be replicated in Vermont schools

Pilot School Selection - Milton Elementary-Middle School (MEMS)

- Demographics representative of Vermont schools (46\% free \& reduced lunch program); school administration supportive of an SBSP; no existing dental education ("Tooth Tutor") program per Vermont Office of Oral Health

\section{Methods}

Survey - distributed via students (hard copy) and school-wide e-mail

- Assessed barriers to dental care in this rural Vermont community

- Evaluated parental knowledge and attitudes regarding sealants and SBSP

- Identified areas for future education and intervention

Statistical method

- Descriptive analysis of overall response and subgroups, including those or

Medicaid, those eligible for free lunch, and those without a dental home

- Independent sample T-tests to compare differences in means between groups

Oral Health Education

- Age-appropriate presentation to 108 second-graders about oral health

- Interactive activity to teach brushing and flossing techniques

- Stressed importance of habits to improve oral health

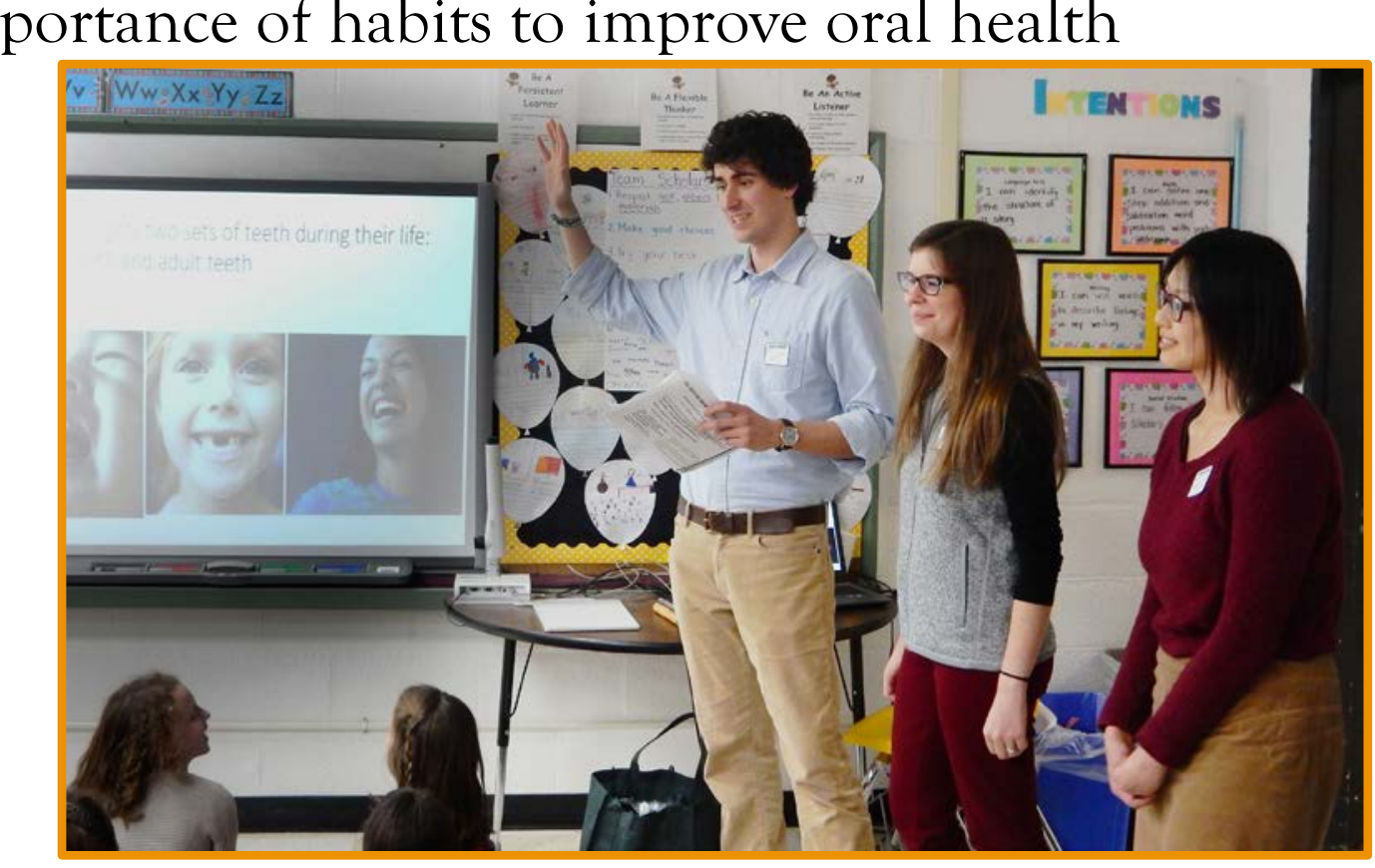

\section{Results}

131 parents responded, representing 204 children

\begin{tabular}{|l|c|c|c|}
\hline \multicolumn{1}{|c|}{ Demographics } & $\%$ & $\mathbf{n}$ & \% interest in SBSP (n) \\
\hline Children eligible for free/reduced lunch & 17.7 & 23 & $60.9 \%(14)$ \\
\hline Does not have a dental home & 7.7 & 10 & $80.0 \%(8)$ \\
\hline Medicaid-funded dental care & 27.7 & 36 & $50.0 \%(18)$ \\
\hline
\end{tabular}
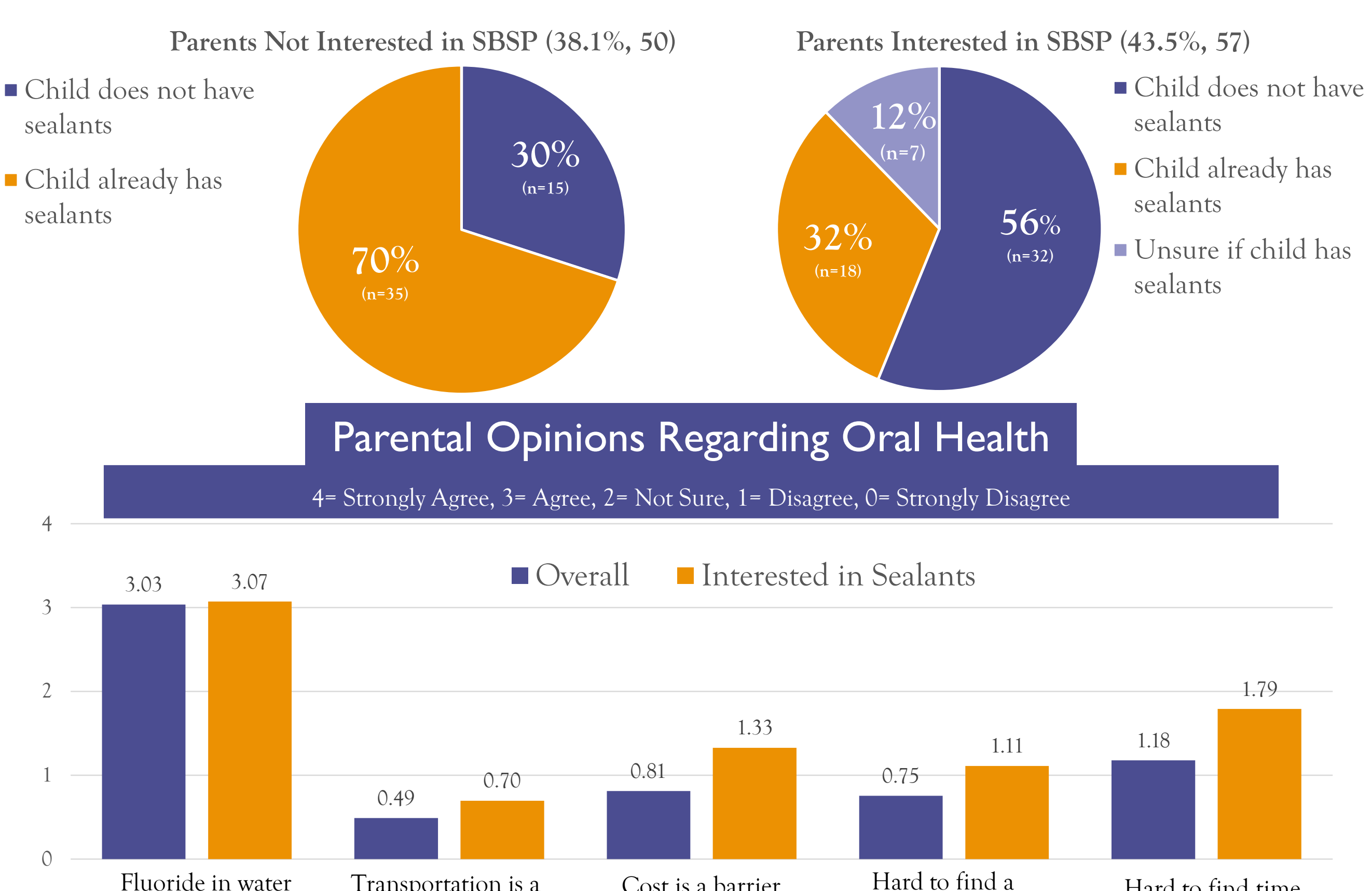

- Overall Interested in Sealant
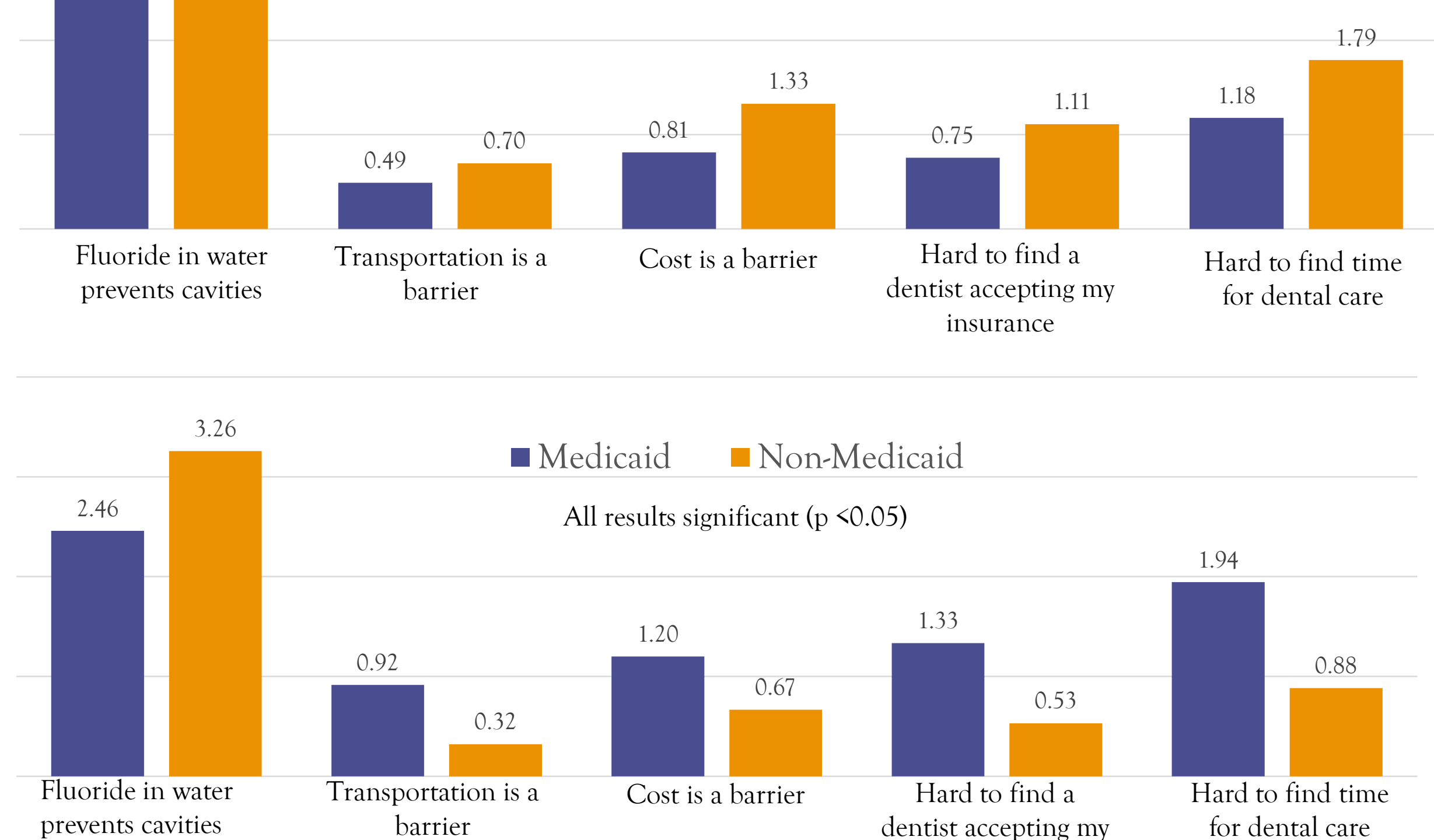

Medicaid $\quad$ Non-Medicaid All results significant $(p<0.05)$

Reasons for Refusal
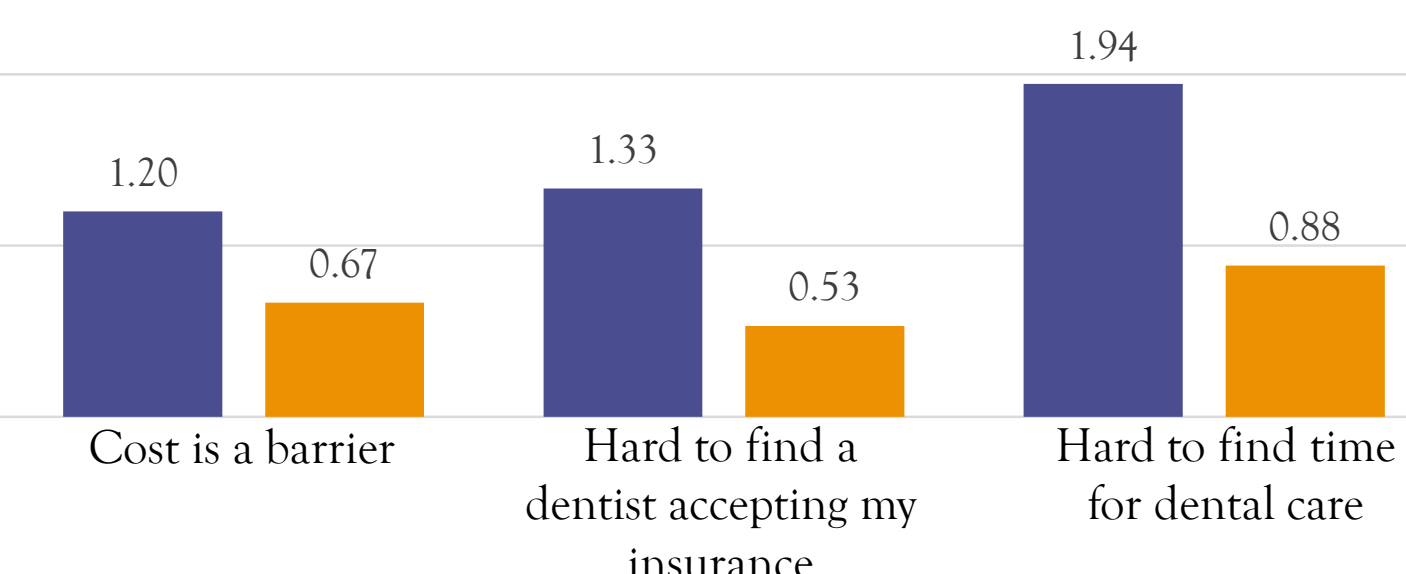

- It is not the school's responsibility to provide any services for children other than to provide them a well-rounded education"

- "I would prefer to be there with them and to only have one dentist consistently working with my children
Discussion \& Conclusions

\section{Key Survey Findings}

- Barriers to dental care were more pronounced in those who were:

- Eligible for free lunches at school

- Paying for dental care through Medicaid

- Without a dental hom

- Parents in these groups expressed as much or more interest in an SBSP

compared with parents not in these groups

- Those who expressed less support for the statement "fluoride in drinking water prevents cavities" were equally likely to be interested in an SBSP as others

- $43.5 \%$ of parents were amenable to an SBSP

- Majority of uninterested parents had children who previously received sealants and had dental homes

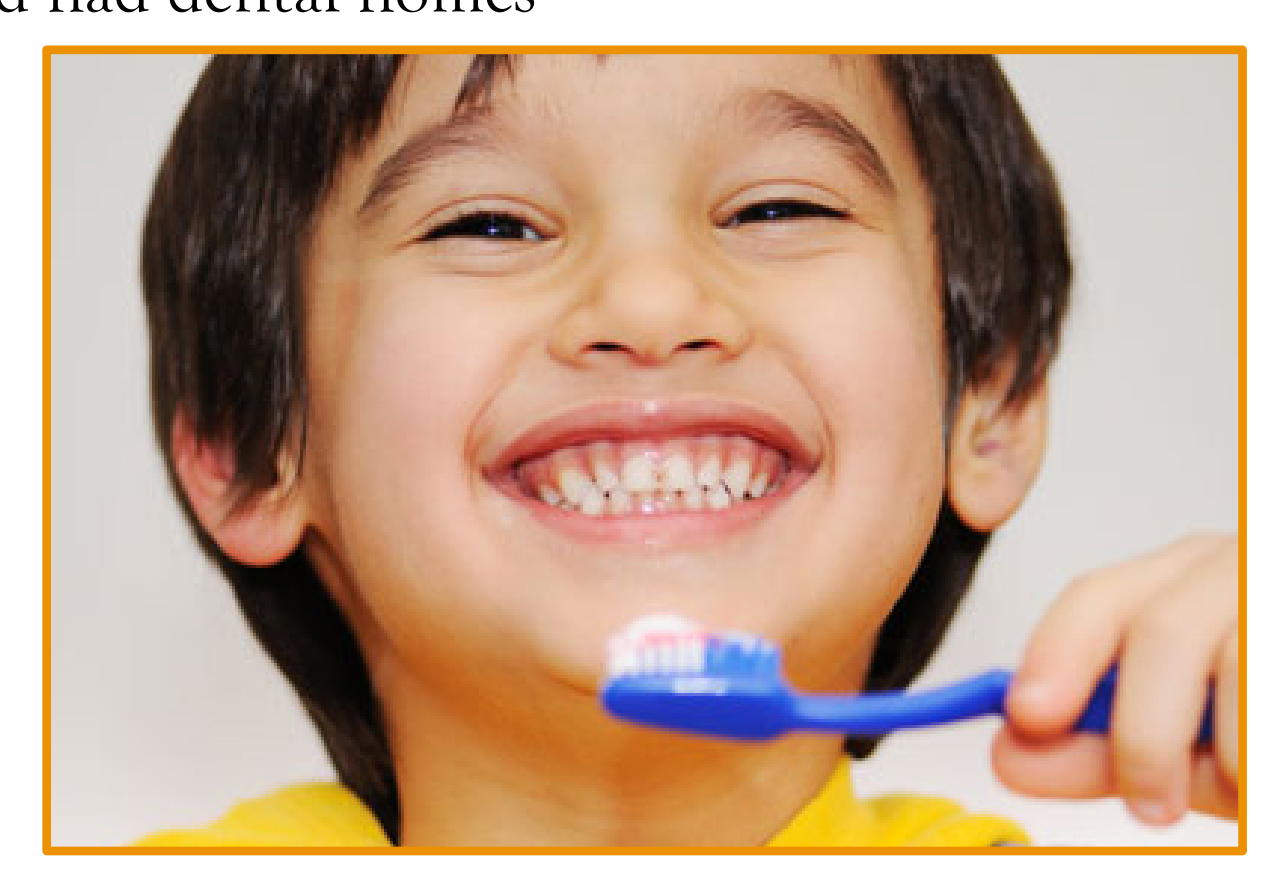

Limitations

- Survey could not be linked to individuals who enrolled in the SBSP pilot

- Could not objectively measure the oral health of respondents' children

Conclusions \& Future Directions

- Engagement of local stakeholders (school faculty, administration, parents,

dentists, public health officials) essential for success

- Suggest evaluating perceptions at schools with "Tooth Tutors" (dental education programs) to determine receptivity to SBSPs

\section{References}

\section{Community Health Needs Assessment UV Mealth.org. May 30, 2013 ,}

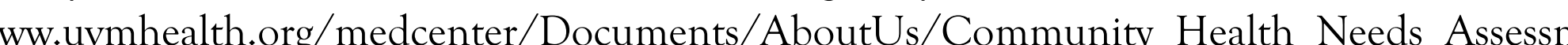

2. Evidence-Based Clinical Recommendations for the Use of Pit-and-Fissure Sealants.

Beauchamp, Jean et al. The Journal of the American Dental Association, Volume 139, Issue 3, 257 - 268 3. Treventing Der

4. Department of Vermont Health Access. "Public Announcement Dental Hygienists." dvha.vermont gov September 4, 2015 .

Acknowledgements We would like to thank Robin Miller, RDH, MPH, Vermont Oral Health Director; Staff and
Administration at Milton Elementary \& Middle School; Vermont State Dental Association; Rajan Chawla; Thomas De 